\title{
OCULAR LEPROSY IN INSTITUTIONALIZED NIGERIAN PATIENTS
}

\author{
J. A. EBEIGBE and F. KIO \\ Department of Optometry, University of Benin, P.M.B 1154, Benin, Edo State 300001, Nigeria
}

Corresponding Author: Dr. Jennifer Ebeigbe

Email: jenniferebeigbe@yahoo.com

Conflict of Interest: None declared

\section{SUMMARY}

Objective: This study was aimed at presenting the profile of ocular lesions observed in the in-mates on multidrug treatment, of a leprosy rehabilitation centre in Nigeria.

Design: Cross-sectional.

Method: One hundred patients were selected by systematic random sampling. Sixty-nine had ocular involvement and were the subjects of this study. The age range was 15 to 80 years with a mean age of 51 years. There were 57 males $(82.6 \%)$ and 12 females $(17.4 \%)$. The range of duration of treatment was two months to 30 years, with a mean of 15 years. Examination of the anterior and posterior segments of the globe and its adnexa was carried out using Penlight, magnifying loupe and direct ophthalmoscope. Visual acuity was recorded using the Snellen charts.

Results: Lepromatous leprosy patients had the greatest incidence of ocular lesions. Ocular lesions were more in patients who have had leprosy for $\geq 15$ years. Madarosis (72.5\%) and lagophthalmos (29.0\%) were the commonest lesions. Corneal involvement was seen in $36.2 \%$. Conjunctivitis in $14.5 \%$. Trichiasis in $10.1 \%$ and ectropion in $8.7 \%$. $17.4 \%$ were legally blind $(\mathrm{VA} \leq 3 / 60)$ in the better eye, and $17.4 \%$ had cataract in at least one eye. There was no statistically significant difference in the incidence of ocular lesions among males and females, and between patients with Lepromatous and Tuberculoid leprosy.

Conclusion: Ocular complications are common and sight threatening in leprosy patients. Regular screening and outreach by eye care providers should be incorporated into leprosy care programmes.

Keywords: Leprosy, Madarosis, Complication, Lagophthalmos, Blindness

\section{INTRODUCTION}

Leprosy is a chronic infectious disease that primarily affects the peripheral nerves, the skin, upper respiratory track, eyes, feet, hands and the nasal mucosa. The mode of transmission is via the respiratory route, mainly through nasal droplets and prolonged body contact.
Bad housing conditions, domestic over crowding, malnourishment and poor feeding habits are risk factors. No racial predilection is known. ${ }^{1}$

Leprosy has the highest incidence of ocular complications of all systemic diseases. The prevalence of leprosy in the world has been estimated at 10-12 million and the number of individuals with deformities at between 2 to 3 million. ${ }^{1}$

Leprosy is known to occur in all ages, from early infancy to old age. Visual disability is often compounded by other disabilities, particularly sensory impairment and deformity of the extremities. ${ }^{2}$ The incidence of ocular complications of leprosy is known to be influenced by a number of factors: anti - leprosy drug treatment, the type of leprosy, duration of disease and the eye treatment received. ${ }^{3,4}$

Ocular lesions in leprosy can be classified into two groups. The first group is potentially sight threatening (PST) and the second group, non sight threatening (NST). PST lesions comprise of lagophthalmos and its sequelae, corneal hypoaesthesia and its sequelae, chronic iridocyditis and its sequelae and scleritis. Non sight threatening lesions such as loss of eyebrows and eyelashes have no visual significance, but contribute to the stigma which these patients endure. ${ }^{5}$ Leprosy is one of the leading causes of corneal hyposensitivity ${ }^{6,7}$ and cataract has been shown to be a major cause of blindness among leprosy patients. ${ }^{8}$

In 1981, the World Health Organization (WHO), recommended a standard treatment multidrug therapy (MDT) for the treatment of leprosy, consisting of Dapsone, Rifampicin and Clofazimine.

\section{MATERIALS AND METHODS}

This was a cross sectional study of inmates of the Ossiomo leprosarium, Edo state, Nigeria, in May 2007. Ethical approval was obtained from the departmental ethics committee. One hundred patients were selected by systematic random sampling using the register of inmates as the sampling frame. 
This was done by selected every third patient on the register of inmates, which contained 300 names. Informed consent was obtained from the patients before the commencement of the study. Out of the hundred patients selected, 69 had ocular involvement and were used as sample population for this study. The medical records of the patients provided information on the name, age, sex, type and duration of the disease as well as the duration of treatment using the multi - drug therapy (MDT). All the patients in the leprosarium were on the MDT. Patients were grouped according to the type of leprosy they had.

The subjects were examined for ocular diseases associated with leprosy. Both eyes of the patients were examined. The examination included visual acuity with the Snellen charts and those with vision less than 3/60 in the better eye were categorized as blind, according to WHO standard. Examination of the ocular adnexae and external structures was done using a Pen torch, and a 25D magnifying loupe. The fundus and internal structures were also examined with a direct ophthalmoscope. Corneal sensation was tested with a wisp of cotton wool. Corneal ulcers were stained with flourescein dye and examined under a Burton lamp with cobalt blue filter.

Data was analysed in percentages using an electronic calculator. The Fisher's exact test was used for statistical analysis, Relative risk and 95\% Confidence interval were also determined

\section{RESULTS}

Only patients with ocular complications were included in this study. This amounted to sixty-nine out of the one hundred patients randomly selected. There were 57 males $(82.6 \%)$ and 12 females $(17.4 \%)$. This gave a male to female ratio of $4.8: 1$. There were $52(75.4 \%)$, patients with lepromatous leprosy, 10 (14.5\%) with borderline leprosy and seven (10.1\%) with tuberculoid leprosy (Table 1). Age ranged between 15 and 80 years, with a mean age of 51 .

Majority of the patients had multiple lesions. Madarosis $(72.5 \%)$ and lagophthamos $(29.0 \%)$ were the commonest lesions, and were predominant in the lepromatous type of leprosy, as shown in the table. There was no statistically significant difference between the prevalence of ocular lesions in males and females.

Table 1 Distribution of Ocular Lesions According to Leprosy Type

\begin{tabular}{|l|c|c|c|c|}
\hline Eye Lesions & $\begin{array}{l}\text { Lepromatous } \\
\text { leprosy (n=52) } \\
\text { Number (\%) }\end{array}$ & $\begin{array}{l}\text { Border line lep- } \\
\text { rosy (n=10) } \\
\text { Number (\%) }\end{array}$ & $\begin{array}{l}\text { Tuberculoid } \\
\text { leprosy (n=7) } \\
\text { Number (\%) }\end{array}$ & $\begin{array}{l}\text { Total (n=69) } \\
\text { Number (\%) }\end{array}$ \\
\hline Madarosis & $36(69.2)$ & $10(100.0)^{`}$ & $4(57.1)$ & $50(72.5)$ \\
\hline Lagophthomos & $13(25.0)$ & $3(30.0)$ & $4(57.1)$ & $20(29.0)$ \\
\hline Ectropion & $6(11.5)$ & 0 & 0 & $6(8.7)$ \\
\hline Entropion & $2(3.9)$ & 0 & $1(14.3)$ & $3(4.4)$ \\
\hline Trichiasis & $7(13.5)$ & $2(20.0)$ & 0 & $9(13.0)$ \\
\hline Conjunctivitis & $10(19.2)$ & $1(10.0$ & 0 & $11(15.9)$ \\
\hline Corneal opacity & $16(30.8)$ & 0 & 0 & $16(23.2)$ \\
\hline Corneal ulcer & $9(17.3)$ & 0 & 0 & $9(13.00$ \\
\hline Iritis & $2(3.9)$. & 0 & 0 & $2(2.9)$ \\
\hline Cataracts & $12(23.1)$ & 0 & & $12(17.4)$ \\
\hline
\end{tabular}

Similarly, there was also no statistically significant difference between the prevalence of the different ocular lesions between the patients with lepromatous and tuberculoid leprosy (Table 2). About a quarter (73.9\%) of the patients with ocular lesions had had leprosy for more than 15 years, and these were mainly in the lepromatous group. Those who have had leprosy for less than 15 years were $26.1 \%$. Out of the $36.6 \%$ of cases that had corneal involvement, $23.2 \%$ had opacities and $13.0 \%$ had ulcers. Chronic conjunctivitis was $16.0 \%$, uveal involvement was of suspected cases of iritis $(2.9 \%)$. Seventeen point four percent were categorized as legally blind (vision $\leq 3 / 60$ in the better eye). Cataract was present in at least one eye in $17.4 \%$ with a resultant VA of less than $3 / 60$.

Table 2 Comparison of ocular findings in patients with lepromatous and tuberculoid leprosy 


\begin{tabular}{|l|c|c|c|c|c|}
\hline $\begin{array}{l}\text { Ocular } \\
\text { Lesion }\end{array}$ & $\begin{array}{l}\text { Lepromatous } \\
\text { Leprosy(n=52) } \\
\text { Number (\%) }\end{array}$ & $\begin{array}{l}\text { Tuberculoid } \\
\text { Leprosy(n=7) } \\
\text { Number (\%) }\end{array}$ & P-value & RR & CI \\
\hline Madarosis & $36(69.2)$ & $4(57.1)$ & 0.7 & 1.1 & $0.9-1.3$ \\
\hline Lagophthmos & $13(25.0)$ & $4(57.1)$ & 0.2 & 0.8 & $0.6-1.1$ \\
\hline Ectropion & $6(11.5)$ & 0 & 1.0 & 1.2 & $1.0-1.3$ \\
\hline Entropion & $2(3.5)$ & $1(14.3)$ & 0.3 & 0.8 & $0.3-1.7$ \\
\hline Trichiasis & $7(13.5)$ & 0 & 0.6 & 1.2 & $1.0-1.3$ \\
\hline Conjuctivitis & $10(19.2)$ & 0 & 0.6 & 1.2 & $1.0-1.3$ \\
\hline Corneal opacity & $16(30.8)$ & 0 & 0.2 & 1.2 & $1.1-1.4$ \\
\hline Corneal Ulcer & $9(17.3)$ & 0 & 0.2 & 1.2 & $1.0-1.3$ \\
\hline Iritis & $2(3.9)$ & 0 & 1.0 & 1.1 & $1.0-1.3$ \\
\hline Cataracts & 1223.1 & 0 & 0.3 & 1.2 & $1.0-1.3$ \\
\hline
\end{tabular}

\section{DISCUSSION}

The $69 \%$ prevalence of ocular complications found in this study is in agreement with other Nigerian studies where high prevalence of $63 \%, 96.7 \%$ and $73 \%$ have been reported. ${ }^{9-11}$ A prevalence of $62 \%$ was reported by Kagame $^{5}$, while $74 \%$ and $80 \%$ were reported by Malla et al ${ }^{12}$ and Prasad et a ${ }^{13}$ respectively from other parts of the world.

Ocular involvement in this study was more in the lepromatous type of leprosy than in the other types of leprosy. This pattern is similar to findings from studies done in the United States ${ }^{14}$ and Brazil ${ }^{15}$. Most of the patients seen in this study had multiple lesions.

Madarosis was the most common ocular lesion in our study accounting for $72.5 \%$ of the cases. This was also reported by Johnstone et al who observed a prevalence of $59 \%$ for madarosis. ${ }^{5}$ Although, loss of eyebrows is a cosmetic blemish, it may be a useful clue, especially in lepromatous leprosy where it is more common. ${ }^{16,17}$

Another common ocular lesion was lagophthalmos which occurred in $29.0 \%$ of the cases. Lagophthalmos is reported as common in most studies on leprosy ${ }^{12,14,15}$ and should be one of the primary indicators for monitoring ocular disability in leprosy, as it presents early in the course of the disease.

Lagophthalmos leads to exposure of the cornea, micro traumata, secondary infections and ultimately progressive opacification of the cornea. ${ }^{16,17}$ Corneal involvement was recorded in 25 patients $(36.2 \%)$ as shown in Table 1. A quarter of the patients had some amount of corneal hypoaesthesia. Corneal hypoaethesia is a potentially serious complication of ocular leprosy and is secondary to trigeminal nerve damage. It may be seen in all forms of leprosy. ${ }^{17}$
All $23.2 \%$ of corneal opacity was in the lepromatous group as well as the $13.0 \%$ that had corneal ulcers. The ulcers could be due mainly to exposure keratitis, which is secondary to lagophthalmos, or to a lesser extent to reduced corneal sensation or trichiasis. Corneal involvement is very common in leprosy and is potentially sight threatening.

A lot of cases of blindness recorded in leprosy are due primarily to corneal opacity. ${ }^{8,9}$ Corneal opacity was recorded in $23.2 \%$ of our study sample and all were in the lepromatous group. Corneal involvement in leprosy is known to be influenced by factors such as lagophthalmos, ectropion, and corneal anaesthesia. Trichiasis $(10.1 \%)$ and ectropion $(8.7 \%)$ were found only in the lepromatous group. Other rare corneal changes such as enlargement and beading of corneal nerves and iris pearls reported in previous works were not examined for in this study because of the limitation of our instrumentation.

Cataract was recorded in $17.4 \%$ of cases, and these were all in the lepromatous group. Cataract in leprosy patients is usually due to age or extensive use of steroid; rarely does it occur as a complication of the disease process itself. Many studies ${ }^{8,9}$ have reported cataract as the leading cause of blindness in leprosy, while others have reported corneal opacity. ${ }^{12}$ Blind leprosy patients have a 4.8 -fold excess risk of dying compare to non blind leprosy patient of the same age. ${ }^{1}$ This could be one reason why few blind leprosy patients are seen.

Uveal involvement was recorded by inference in only two patients $(2.9 \%)$. The patients' records showed they were on medications for acute iritis. The $2.9 \%$ of uveal involvement is contrary to findings in other studies where prevalence of $7.3 \%{ }^{15}, 10.1 \%{ }^{16}$, and of $18.1 \%{ }^{17}$ were recorded. This could be attributed to the fact that standard instrumentation like the slit lamp bio microscope for proper examination of the uveal was not used in this study, and as such, other cases could have been 
missed. This was a major limitation. Chronic conjunctivitis $(16.0 \%)$ was another ocular manifestation recorded in our study. Previous studies have also recorded a significant incident of conjunctivitis in leprosy patients.

A preponderance of males with ocular lesions in leprosy has been reported in a previous study by Myogo et al. ${ }^{17}$ Our study showed a similar trend although not statistically significant. One reason suggested for this preponderance in previous studies is that the male lifestyle generally exposes them to greater risks of infection, while women may tend not to seek medical help even when it is required. ${ }^{18,19}$ Other ocular manifestations reported in previous studies include dry eye, iris atrophy, panophthalmitis and phthisis bulbi. None of these, however, was found in this study.

This study had some limitations that may affect direct comparison with the findings of previous studies. ${ }^{20}$ Inadequate instrumentation for proper evaluation of some ocular complications like iritis may have resulted in a low incidence of these conditions. Similarly, the nature of the study being cross sectional makes it difficult to clearly define whether the complications started before or during treatment. Despite these limitations, cross sectional studies like ours are beneficial in providing data for planning necessary interventions to improve ocular care in leprosy patients.

\section{CONCLUSION}

Sight threatening complications are common in patients suffering from leprosy even when they are on multi - drug therapy although it is possible that the complications developed prior to therapy. Most of these blinding complications can be prevented with early diagnosis and prompt treatment. Regular eye screening and outreach programs should be integrated into leprosy care programmess with a view to preventing and treating avoidable causes of blindness.

\section{REFERENCES}

1. Courtright PD, Lee HS, Lewallen S. Excess mortality associated with blindness in leprosy patients in Korea. Leprosy review. 1977; 68 (4): 326 - 330.

2. Kondo S. Ocular Impairment in Leprosy. Nihon Hansenbyo Gakkai Zashi. 2004; 73(1): 23-35.

3. Johnstone PA, George AD, Meyer W. Ocular lesions in leprosy. Am J. Ophthalmol. 1991; 23(8): $287-303$.

4. Hogeweg M, Keinwn J E. Prevention of blindness in leprosy and the role of vision 2020 program. Eye. 2005; 19:1099 -1105.
5. Kagame GK .Ocular leprosy in Africa. Soc. Sci Med.1993; 17 (22): 1734 -1742.

6. Gupta HR, Shakya S, Shah M, Pradhan HM. Leprosy Blindness in Nepal. Nepal Med Coll. J. 2006; 8(2): $140-142$.

7. De Souza FS, de Almeida LN, Costa JP, da Rocha PV, de Almeida Sobrinho EF. Frequency of Ocular changes in patients with Hansen's disease living in a colony hospital. Arq Bras Oftalmol. 2005;68(3):369-372.

8. Ridley DS, Jopling WH. Classification of leprosy according to immunity: a five group system. Int $J$ Lepr. 1966; 34:255-273.

9. Nwosu SN, Nwosu MC. Ocular findings in leprosy patients in Nigeria. East Afr. Med. J. $1994 ; 71$ (7); $441-444$

10. Waziri - Erameh MJ, Omoti AE. Ocular leprosy in Nigeria a survey of an Eku leprosorium. Trop Doct. 2006; 36(1): $27-30$

11. Mpyet C, Solomon AW. Prevalence and 12 causes of blindness and low vision in leprosy villages of northeastern Nigeria. $\mathrm{Br} \quad J$ Ophthalmol.2005 89(4):417-9

12. Mella OK, Bandt F, Anten JGF. Ocular findings in Leprosy patients in an institution in Nepal (Khokana). Br. J Opthalmol.1981; 65:226 - 230.

13. Prasad VN, Narain M, Mukhija RD, Bist K, Khan MM. A study of Ocular complications in leprosy. Indian J. lepr, 1984; 56 (2); 241-245.

14. Dana MR. Hochman MA, Viana MA, Hill CH, Sugar J. Ocular manifestations of leprosy in a non institutionalized community in the United States. Arch Ophthalmol. 1994; 112(5): 626-629.

15. Orefice F, Boratto LM. Clinical Ocular study in leprosy patients at a sanitary dermatological hospital in Brazil. Indian J. lepr. 1998; 70(2): 189 - 95.

16. Malu KN, Malu AO. Blindness in leprosy patients of Kaduna State; Northern Nigeria. Trop Doct. 1997; 24(4): 181 - 183

17. Myogo CE, Bella- Hiag AL, Ellong A, Achu JH, Nkeng PF. Ocular complications of leprosy in Cameroun. Acta Ophthalmol. Scand. 2001; 79(1): $31-33$.

18. Lamba PA, Rotatgi J, Bose S. Factors influencing corneal involvement in leprosy. Int. J lepr other mycobact Dis. 1987; 55(4):667-671.

19. Sanjiv D, Rajiv D, Desai NC, Shoba L, Kumar K. Ocular findings in the inmates of a leprosy rehabilitation centre. Indian J Ophthalmol 1989;37(2):969

20. Courtright PD. Defining the magnitude of ocular complications from leprosy: problems of methodology. Int J Lepr other mycobact dis. 1987; 55(4) 667-71. 